\title{
CONFLICTOS Y NEGOCIACIONES ENTRE LOS EMPRESARIOS HARINEROS DE LA REGIÓN ANDINA Y LOS DE LA COSTA CARIBE COLOMBIANA, 1904-1912*
}

\author{
CONFLICTS AND NEGOTIATIONS BETWEEN THE \\ FLOUR ENTREPRENEURS OF THE ANDEAN REGION \\ AND THE COLOMBIAN CARIBBEAN COAST, 1904-1912
}

\author{
Andrea Carolina Miranda Pestana \\ Instituto Internacional de Estudios del Caribe, Cartagena, Colombia <a.mipe@hotmail.com> \\ Raúl Román Romero \\ Universidad Nacional de Colombia, Bogotá, Colombia <rromanr@unal.edu.co>
}

Resumen. Este artículo analiza las relaciones políticas que se tejieron entre la elite empresarial de Cartagena y Barranquilla, y los gobiernos de Rafael Reyes y Carlos E. Restrepo de 1904 a 1914, así como las tensiones que se presentaron entre los empresarios de la costa caribe colombiana y los de Bogotá por la defensa de sus intereses, que cada uno de estos sectores empresariales colocó frente a la política económica durante estos años. El centro de estas tensiones económicas tiene como núcleo la producción y el comercio de harina; en este sentido, el debate que se presenta en torno a este tema reproduce rivalidades que se dieron desde finales del periodo colonial, y revive las confrontaciones por los mercados, la política y el modelo económico que se impone en el país entre 1904 y 1914.

Palabras clave: elite empresarial; conflictos regionales; relaciones políticas; harina.

Abstract. This article discusses the political relations which were woven between the flour entrepreneurs of Cartagena and Barranquilla, and the political views of Rafael Reyes and Carlos E. Restrepo between 1904 and 1912. It also examines the tensions that arose between the Caribbean Coast entrepreneurs and those of Bogota, whom, everyone on each side, defended their own business interests, when facing the economic politics of those years. The center of these economical tensions has as an epicenter the production and distribution of flour, in this sense, the debate on this matter, recreates the rivalries that took place since the end of the colonial era and

\footnotetext{
* Este artículo forma parte de los proyectos de investigación La Consolidación de la Unidad Nacional versus la Fragmentación Regional. El Caso de San Andrés, Providencia y Santa Catalina. 1909-1914, Coordinación de Investigación, sede Caribe, de la Universidad Nacional de Colombia, código 10505, e Inventando Separatismos. Aproximación a las Relaciones Políticas entre el Gobierno Central y la Elite Empresarial de Cartagena y Barranquilla. 1904-1914, Universidad de Cartagena, Facultad de Ciencias Humanas, Programa de Historia.
}

Am. Lat. Hist. Econ., año 21, núm. 3, septiembre-diciembre, 2014, pp. 176-200 
revives the confrontations for markets, politics and the implemented economic model in the country during 1904 and 1914.

Key words: business elite; regional conflicts; political relations; flour.

Fecha de recepción: septiembre de 2013. Fecha de aceptación: febrero de 2014.

\section{INTRODUCCIÓN}

0 i bien el tema de los conflictos locales y regionales ha sido motivo de preocupación para la historiografía de diferentes países de América Latina, no fue sino hasta los años setenta y ochenta cuando las historias regionales y sus conflictos con los centros de poder ocuparon un lugar central en la historiografía de varios países de la región; México, Argentina, Perú y Venezuela, entre otros, tuvieron desarrollos importantes en estas temáticas. En el caso mexicano, Don Coerver (1977) sostiene que los estudios de los conflictos región-nación perpetuaron la imagen de un gobierno central ejerciendo un control absoluto sobre las autoridades locales y federales en las provincias. Coerver propuso que las relaciones provincia-Estado central fueran estudiadas en función de factores económicos, y no exclusivamente a partir del análisis de las estrategias políticas y militares empleadas por el gobierno central para imponerse en el espacio provincial (p. 567). Carlos Martínez Assad (1978), también para el caso mexicano, resaltó las estrategias de tipo político creadas por el poder local ante el control ejercido por el gobierno central. Su estudio replantea la relación entre el gobierno central y la región por encima de las segregaciones que pretendían las localidades; además, propone que ante la centralización las localidades establecen alianzas políticas coyunturales con el fin de beneficiarse de las disposiciones que en materia económica y política se emiten desde el centro del país (p. 14). Por su parte, Tania Hernández Vicencio analizó la participación de los empresarios de Tijuana, México, demostrando que la falta de acuerdo para fundar un grupo financiero local y su incapacidad para consolidarse como un grupo fuerte y cohesionado de cara al mercado nacional evitaron el fortalecimiento de una elite regional en el estado de Tijuana.

Irma Corrales (1982, p. 120) demuestra que el predominio del poder central en México no es sinónimo de ausencia del poder local. Hay un margen de autonomía en la decisión y ejecución de acciones, así como en la promoción de intereses en el ámbito local; de esta forma lo dejan ver los conflictos y negociaciones alrededor de las disposiciones emitidas desde 
el gobierno central y la puesta en marcha por parte de funcionarios, elites locales y autoridades federales.

Investigaciones de Jeffrey Rubbin (2003) sobre México demuestran que el dominio estatal puede ser definido como continuo y cambiante, no como producto exclusivo de un centro que lo controla todo, ni de estructuras fijas de negociación y dominios políticos, sino de varios sitios y formas cambiantes de dominación y resistencia. ${ }^{1}$

Para Centroamérica, Arturo Taracena Arriola $(1997,2000)$ se aleja de planteamientos que asocian la región únicamente con entidades administrativas y con espacios geográficos; propone que la región es una construcción social en donde entran en contradicción los intereses de las elites locales con el proceso económico de los polos de desarrollo.

Para el caso argentino José Carlos Chiaramonte, Guillermo E. Cussianovich y Sonia Tedeschi (1993), Noemí M. Girbal-Blancha (1994) y Juan Carlos Garavaglia (2007), entre otros, han centrado la mayoría de sus estudios en la provincia-región, entendida como la extensión espacial de la ciudad y el área rural circundante. Para ellos, si bien es posible concebir esta unidad sociopolítica como una categoría de análisis utilizada para comprender el proceso de gestación de los Estados nacionales durante la primera mitad del siglo XIX, también es de utilidad al momento de estudiar las dinámicas económicas y políticas durante las primeras décadas del siglo XX (Girbal-Blacha, 1994); para el caso de Ecuador véase Hidalgo (2008). Los conflictos económicos y políticos entre lo provincial-local y lo central tienen lugar, según esta tendencia, cuando en esas relaciones los actores, sus intereses o lealtades están espacial y estructuralmente diferenciados, esto como consecuencia del origen colonial de los límites territoriales administrativos. Las naciones independientes que surgieron en Hispanoamérica lo hicieron siguiendo algunos de esos límites coloniales, y generalmente conservaron en su interior otras divisiones geopolíticas administrativas preexistentes (Balan, 1978, p. 49).

En el caso de Perú los conflictos regionales siguieron las lógicas de las rivalidades que habían tenido los territorios durante el periodo colonial, asociadas a las actividades productivas, la configuración de un mercado interno y del circuito comercial. No obstante, con la independencia estas rivalidades se exacerbaron y generaron luchas civiles y confrontaciones por el manejo del poder estatal. Recientemente, Elizabeth Hernández García (2008) demostró, a partir del análisis de la elite de Piura, la existencia

${ }^{1}$ La perspectiva de los análisis regionales, según este autor, sugiere que deben ampliarse los conceptos de región y política para descentrar el régimen y dar a la cultura y a las prácticas cotidianas un lugar fundamental al hablar del poder. 
de diversos conflictos de intereses entre grupos de poder regionales que pugnaban por la autonomía política.

Condori (2010a, 2010b), Contreras (1987), Chambers (1997, 2003) y Hunt (1984) han analizado a las elites arequipeñas y los casos importantes de las pugnas regionales en Perú a partir de los desempeños productivos y las rivalidades económicas de algunas regiones como la sierra central, el sur y la costa, en las que se presentaron coyunturas históricas diferentes que propiciaron desarrollos económicos de importancia que amenazaban o desplazaban la estabilidad económica y la capacidad de influencia política de sus regiones rivales.

Para el caso venezolano, Germán Cardozo (2005) sostiene que el fracaso del modelo centralista que, por más de un siglo, ha dominado el aparato político administrativo del Estado nacional en los distintos países de América Latina, ha obligado a las entidades menores, a las municipalidades y provincias a volver sus miradas a su pasado y proceder a la reconstrucción de sus identidades regionales. En Venezuela las rivalidades entre Zulia y Caracas tomaron dimensiones importantes, la primera con el interés de fortalecer su autonomía y modelo económico y la segunda para imponer un poder centralizado (Urdaneta, 2006).

Cardozo (1998) reconoce que, una vez iniciado el proceso independentista, los proyectos políticos y económicos de las clases dirigentes asentadas en las antiguas capitales virreinales, gobernaciones o capitanías generales, ejercieron una centralización cada vez más radical del poder. Las regiones históricas venezolanas conservaron sus antiguas estructuras sociopolíticas durante el movimiento emancipador, además de reclamar su presencia a la hora de definir la nueva forma política que adoptaría la capitanía general y en la conformación de una estructura de poder que sustituya al marco jurídico-político monárquico.

En Colombia el tema también ha ocupado la atención de algunos historiadores, aunque la historiografía sigue teniendo el sesgo de las historias nacionales construidas desde los centros de poder; el caso específico de las confrontaciones entre la costa caribe colombiana y la región centroandina, liderada desde la ciudad de Bogotá, lo que ha incidido de manera determinante en la construcción de una historia del centro del país que se impuso como historia nacional y en las limitaciones de desarrollo de una historiografía regional, que ha encontrado serios obstáculos para su progreso en la escasez de fuentes y en la ausencia, hasta hace algunos años, de investigadores sobre la región (Botero, 2003; Colmenares, 1998; Jaramillo, 1997, pp. 129133; Palacio, 1986; Palacio y Safford, 2002; Uribe y Álvarez, 1987).

Entre los trabajos que se han dedicado a los conflictos entre el centro del país y la costa caribe podemos mencionar los de Gustavo Bell (1994), quien los ha explicado a partir de las confrontaciones políticas que se dieron desde 
los inicios del proceso de independencia. Para él, la independencia de Cartagena en 1811 evidenció la posibilidad de construir un proyecto regional desde esta ciudad, sometiendo a las localidades circundantes de Santa Marta y Riohacha, que se mantenían fieles al rey de España; sin embargo, las elites de la ciudad fracasaron, pues encontraron en las diferencias de los intereses locales el principal obstáculo para este proyecto regional.

Bell (1991) sostiene que los intereses diversos y las rivalidades en el interior de la región Caribe, en especial entre Cartagena, Santa Marta y Mompós, fueron aprovechados por el gobierno central en diferentes coyunturas separatistas del siglo XIX para debilitar cualquier intento de integración regional. En igual sentido, Jorge Conde $(1994,2009)$ señaló que estos conflictos en el interior de la región fueron una consecuencia de los intereses particulares que prevalecieron entre estas tres localidades durante los años de la construcción de la primera república de Cartagena.

Alfonso Múnera $(1993,1996)$ en un análisis sobre el proceso de independencia, mostró la existencia de autonomía política en Cartagena, incluso después de haberse creado el virreinato de Nueva Granada en 1739. Esta autonomía llevaría a los comerciantes de Cartagena, años después, a un enfrentamiento con los de Santa Fe de Bogotá y los virreyes, cuando estos intentaron prohibir el ingreso de harinas extranjeras al puerto de Cartagena debido a que se producía en las sabanas de Bogotá. Fue precisamente este enfrentamiento entre diversos modelos económicos lo que llevó a que finalmente Cartagena se insubordinara frente a la autoridad del virrey en 1810, hecho que acarrearía la independencia definitiva de la ciudad un año después.

Raúl Román (2010), al analizar el tema de la crisis de Cartagena en el siglo XIX, sostiene que buena parte del declive económico que se prolongó en el puerto de Cartagena hasta principios del siglo Xx fue el resultado del fracaso de los principales proyectos empresariales de la ciudad, ya que encontraron una fuerte oposición tanto en la política económica del gobierno central, que favorecía los intereses económicos de los productores bogotanos, como también en los intereses de un grupo de comerciantes de aquella capital. A partir de 1832, con la política económica proteccionista del gobierno de Francisco de Paula Santander, se le impusieron fuertes aranceles a la importación de harina, con lo cual los comerciantes cartageneros abandonaron, por varios años, la negociación de este producto en mercados del centro del país (p. 355).

En el siglo Xx, Eduardo Posada Carbó (1999) estudió la creación de la llamada liga costeña, como un movimiento político que agrupa a algunos empresarios de Barranquilla, Cartagena y varios sectores sociales y políticos de la región para defender la autonomía regional frente al gobierno central $\mathrm{y}$, de esta forma, adelantar las acciones conducentes al progreso de la región 
(pp. 331-351). Para Posada esta alianza es una muestra de un regionalismo político y de la defensa de los intereses políticos y económicos de la región.

Aunque estos aportes resultan importantes, aún no tenemos una visión de conjunto que nos permita entender mejor el tipo de confrontaciones y relaciones políticas que se tejieron entre algunas elites de la costa caribe y el gobierno central en las diferentes coyunturas que se dan a lo largo del siglo XIX y principios del XX. Lo que sabemos por estos estudios es que las tendencias radicales y separatistas que se dieron frente al gobierno central establecido en Bogotá en el siglo XIX, con confrontaciones bélicas incluidas, fueron convirtiéndose, para el siglo xx y a medida que se imponía la hegemonía del centro andino, en negociaciones y pactos entre las elites regionales y el gobierno central. Este artículo se propone realizar un aporte a esta temática, analizando una coyuntura clave en el siglo XX, en la que se ponen de manifiesto tensiones y negociaciones entre las elites comerciales de la costa caribe con el gobierno central, representado por los gobiernos de Rafael Reyes y Carlos E. Restrepo entre 1904 y 1914.

Para la realización de este artículo se han consultado varias fuentes, en especial la prensa de Bogotá, Cartagena y Barranquilla para el periodo que se extiende entre 1904 y $1914,{ }^{2}$ y que reposa en los acervos documentales de las bibliotecas Luis Ángel Arango, Nacional de Bogotá y Bartolomé Calvo, así como en el Archivo Histórico de Cartagena; documentos oficiales compuestos por las memorias de los ministerios de Hacienda de los gobiernos en estudio, memorias que reposan en el Archivo Histórico de Cartagena de Indias, enviadas por los diferentes sectores económicos al gobierno para solicitar políticas económicas de acuerdo con sus intereses.

\section{EL GOBIERNO DE REYES Y SUS RELACIONES CON LA ELITE EMPRESARIAL COSTEÑA}

En 1904, Rafael Reyes asumió la presidencia de Colombia en medio de una profunda crisis económica, política y social, pues la reciente guerra entre liberales y conservadores de 1899 a 1902, sumada a los efectos de la separación de Panamá en 1903, dejó muy frágil no sólo la soberanía

${ }^{2}$ De Barranquilla, El Comercio, 31 de julio de 1911; El Progreso, 11 de agosto de 1912; La República, 31 de julio de 1911 y 12 de agosto de 1912. De Bogotá, La Civilización, 10, 15 y 17 de marzo de 1910; La Mañana, 8 de enero de 1910 y La Capital, 12 de enero de 1911; La Crónica, 31 de julio, 22 de agosto y 6 de noviembre de 1912. Acervo documental de la Biblioteca Luis Ángel Arango. De Bogotá, El Tiempo, 30 de octubre de 1912 y El Centro, 25 de febrero de 1913. Biblioteca Nacional de Colombia. De Bogotá, Diario Oficial, 26 de abril de 1912, 30 y 31 de enero de 1913 y de Cartagena, El Mundo Nuevo, 20 de septiembre y 28 de junio de 1912. Archivo Histórico de Cartagena, Colombia. De Cartagena, El Porvenir, 4 de diciembre de 1904; 14, 17 y 21 de febrero y 9 de marzo de 1906. Biblioteca Bartolomé Calvo, Colombia. 
colombiana, sino también la legitimidad del bipartidismo (Román, 2011, pp. 79-98). Rafael Reyes nació en Santa Rosa de Viterbo, una población de Boyacá el 5 de diciembre 1849, desde muy joven se vinculó al negocio familiar que llevó por nombre Elías Reyes \& Hermanos (Mayor, 1999). Esta compañía tuvo como radio de acción la región del Amazonas, donde participó activamente de la explotación de la quina en el momento más importante de sus exportaciones. En 1884 esta empresa entró en crisis y Reyes incursionó en la vida militar, lo que le permitió una participación importante en política, especialmente con el respaldo de Rafael Núñez como presidente, quien lo nombró ministro de fomento.

Después de la muerte de Rafael Núñez en 1894, participó como candidato presidencial, y tras su fracaso aceptó la designación como embajador en Francia, donde se encontraba al momento de la guerra de los Mil Días; de allí se trasladó a México, donde conoció de cerca el proyecto del presidente Porfirio Díaz, quien fue una gran influencia para el modelo de gobierno que impuso en Colombia durante su presidencia. Luego de pasar por México se convirtió en candidato presidencial para después lograr el triunfo. De esta forma, Reyes asume el gobierno con la participación de todos los partidos, impulsando un conjunto importante de reformas políticas, económicas y jurídico-administrativas que no gozarían de la aprobación de algunos sectores políticos y económicos del país.

En términos de su política económica, Rafael Reyes intentó incrementar los ingresos fiscales del gobierno al promover decretos de carácter proteccionista para aumentar el recaudo fiscal; esto le ganó la confianza y la simpatía de hacendados y productores bogotanos, por lo que en 1906 decretó la prohibición de la libre introducción de harina estadunidense en los puertos del Atlántico. ${ }^{3}$

Las reacciones de los empresarios costeños, quienes comerciaban la harina hacia el interior del país, no se hicieron esperar. De inmediato manifestaron su descontento con la medida. El presidente Reyes, que buscaba ante todo la estabilidad de su gobierno, trató de satisfacer las demandas tanto del empresariado costeño como las del bogotano. Esto explica el porqué de los cambios en otras medidas para reglamentar la introducción de harina extranjera.

Reyes expidió el decreto 116 de 1906, en el que estableció que la harina que ingresara a los puertos del Caribe libre de impuestos, una vez que transitara a los mercados locales desde el puerto fluvial de Calamar, debía

${ }^{3}$ Una de las medidas tomadas por el gobierno de Reyes fue convertir los derechos de destilación y degüello en nacionales, lo que obligó a muchos gobernadores de los departamentos de la costa a tomar medidas para no perder ese ingreso de sus rentas departamentales. En el departamento de Bolívar, el gobernador incrementó el pago del derecho de destilación en 25 centavos y el degüello de cada res macho en un peso (El Porvenir, 4 de diciembre de 1904). 
pagar el impuesto suplementario por un valor de ocho centavos por kilogramo. Este derecho suplementario debía cancelarse en la administración de aduana del puerto, en el que se procedía a registrar su llegada; la harina que no estuviera debidamente registrada era considerada de contrabando. Este decreto fue transmitido por telégrafo a las aduanas del Atlántico y publicado en la prensa local desde el momento de su expedición el 5 de febrero de 1906; en la prensa podía leerse: "Artículo $1 .^{\circ}$ : La harina extranjera que salga de los puertos del Atlántico para todos los de río Magdalena, desde Calamar incluso para arriba, ya sea para el consumo local o para el de otras poblaciones, pagará un derecho suplementario de 8 centavos por cada kilogramo" (El Porvenir, 14 de febrero de 1906).

Sólo unos días después de que se quejaran algunos comerciantes costeños, se expidió otro decreto reformando el número 166 (El Porvenir, 17 de febrero de 1906). Este decreto se dirigió explícitamente a satisfacer las demandas de los hermanos Pombo, Diego Martínez y Co., Bartolomé Martínez Bossio y Compañía, Geiseken \& Co., Francisco González y Flohr Price, quienes habían dado un respaldo político a Reyes durante su candidatura a la presidencia (Ripoll, 2003, p. 181):

Harina de trigo para el río Magdalena.

Circular oficial-Urgentísimo-Bogotá, febrero 17 de 1906,

Pombo Hermanos Diego Martínez y C. ${ }^{a}$, Bartolomé Martínez Bossio \& C. ${ }^{a}$, Geiseken \& C. ${ }^{\text {a }}$, Echevarría Salas \& C. ${ }^{\text {a }}$, Francisco Gonzáles \& C. ${ }^{\text {a }}$, Flohr Price Díctese hoy decreto declarando que desde la fecha y hasta el primero de marzo de 1907 puede venir harina americana sin pagar nuevos derechos a todos los puertos del río Magdalena hasta Puerto Berrío, inclusive. Por telégrafo transcríbase hoy.

Decreta Administradores de Aduana Cartagena y Barranquilla

REYES

(El Porvenir, 17 de febrero de 1906).

Este nuevo decreto permitió la introducción de harina al interior del país, pues hasta Puerto Berrío quedaba exento del impuesto suplementario. En consecuencia, sólo se gravó la harina que se destinaba a los lugares que estaban posteriores a este puerto. Esta medida conciliatoria con los empresarios de la costa no contravenía los intereses de los productores de trigo de la meseta bogotana, ya que de Puerto Berrío en adelante, con el pago del impuesto, se incrementarían sustancialmente los costos de comercialización de la harina extranjera, y con el carácter transitorio que le daba vigencia a la medida, de sólo un año y dos meses, los comerciantes de ambas regiones se prepararían para asumir los nuevos costos arancelarios, lo que facilitaría el consumo de la harina del interior. 
El presente decreto regirá desde su expedición y sus efectos durarán únicamente hasta el día 1 de marzo de 1907; de esta fecha en adelante regirán en todas sus partes las disposiciones del decreto número 166 de 5 del presente mes, el cual queda reformado en los términos que expresa el presente. Dado en Bogotá, a 17 de febrero de 1906, ministro de Hacienda y Tesoro, Félix Salazar Reyes (El Porvenir, 21 de febrero de 1906).

Ante la derogación de este decreto, Henrique Luis Román, gobernador de Bolívar y distinguido empresario de la costa, publicó un telegrama en $\mathrm{El}$ Porvenir, en el que destacaba lo conveniente que resultaba esta disposición en la medida en que se conciliaban ambos intereses: el de los distribuidores de harina importada en la costa y el de los productores del interior. Además de esta determinación, resaltó en El Porvenir (9 de marzo de 1906) lo provechoso que sería la supresión de los derechos sobre el ganado y la tagua, que también estaban vigentes. ${ }^{4}$

A partir de la derogación de este decreto, Rafael Reyes afianza sus vínculos políticos con los empresarios costeños estableciendo una serie de negociaciones entre los sectores importadores-exportadores para mantener su estabilidad en el gobierno. Este decreto, aunque sancionado de manera transitoria, siguió vigente muchos años después. $\mathrm{Al}$ parecer, Reyes, con una oposición creciente por parte de los empresarios antioqueños encabezados por Carlos E. Restrepo, no quiso perder el apoyo de los empresarios costeños y, en consecuencia, nunca vigiló que se cumpliera el carácter transitorio del decreto. Luego de las negociaciones con los Estados Unidos por el canal de Panamá, vino su inestabilidad política y posterior renuncia, lo que dio lugar al gobierno provisional de Ramón González Valencia, quien estaba vinculado a las familias de los hacendados bogotanos (El Porvenir, 9 de marzo de 1906, p. 2).

González Valencia convocó a una asamblea nacional que se reuniría en mayo de 1910 y cuya tarea central era modificar la Constitución de 1886. Esta tarea de conciliación entre liberales y conservadores fue conducida en términos generales por el nuevo grupo político, en cuyas filas se unieron los elementos que se denominaban civilistas de ambos partidos y algunos representantes de los grupos empresariales más prósperos del país, entre los que figuraban, en primer plano, los miembros de las elites económicas de Antioquia y de las otras zonas que experimentaban

${ }^{4}$ Cartagena, 19 de febrero de 1906. "Gral. Reyes. Felicítolo por decreto reformatorio del 166 , sobre derecho suplementario a la harina, que ha sido recibido con júbilo por comercio. Así comercio podrá salir de grandes existencias y en la altiplanicie prepararse para mayor producción dentro de un año aunando así ambos intereses. Esto completarse si bien supresión derechos sobre ganado y tagua que esta ofrecida y aguardarse impaciente." 
un crecimiento económico como consecuencia del incremento de las exportaciones de café (Melo, 1996; Román, 2011; véase también Bergquist, 1992, y Calvo y Meisel, 1999). En este punto, Meisel (1999) compara la precariedad en la formación del mercado regional costeño con el caso de la industria antioqueña, que contó con el creciente mercado del territorio de la colonización con nivel adquisitivo derivado de la economía cafetera.

Durante el corto gobierno de González Valencia se iniciaron cambios políticos de importancia, lo que dio lugar a que los productores de harina de la meseta cundiboyacense, organizados en la Junta de Agricultores de Colombia, vieran en él la posibilidad de cumplir las demandas que con la presidencia de Reyes no habían logrado; por eso aprovecharon la ocasión para enviarle un conjunto de solicitudes tendentes a eliminar algunos privilegios que tenían los comerciantes de la costa frente a la producción y comercialización de harina extranjera.

\section{LAS DENUNCIAS Y DEMANDAS DE LOS AGRICULTORES DEL CENTRO DEL PAÍS}

El 17 de marzo de 1910, varios agricultores con residencia en Bogotá y sus alrededores enviaron un memorial al ministro de Hacienda pidiéndole que restableciera el derecho al pago suplementario que recaía sobre la harina y el trigo extranjeros creado desde 1906 (La Civilización, 17 de marzo de 1910). Los firmantes de la solicitud desconocían las causas por las cuales se les otorgaban prebendas a los comerciantes de la costa y se revocaban los aranceles a la harina y el trigo extranjeros, lo que iba en detrimento de los "derechos adquiridos con justo título, con arreglo a las leyes, por personas naturales o jurídicas [que] no pueden ser desconocidos ni vulnerados por leyes posteriores" (p. 3).

Los agricultores del centro del país eran enfáticos en señalar que debían revocarse los artículos 7, 8 y 9 de la Ley 22 de 1908, en los que se autorizaba al gobierno la rebaja o supresión de los derechos de exportación, elevando o disminuyendo el arancel aduanero en defensa de los productos nacionales (La Civilización, 17 de marzo de 1910, p. 3). Para los firmantes, esta ley fue malinterpretada en la medida en que se rebajaba o suprimía el derecho de importación y no el de exportación, "porque disminuye el arancel aduanero en contra y no en defensa de los productos colombianos y porque lo disminuye o quita a favor del trigo o harina yanqui cuando en Estados Unidos se han gravado muchos de los artículos de Colombia" ( $L a$ Civilización, 17 de marzo de 1910, p. 3).

Las demandas de los miembros de la Sociedad de Agricultores del interior del país, liderada por la empresa de Patiño y Montoya Compañía, contemplaban que estaba próximo a ejecutarse el decreto que suprimiría 
el gravamen de diez pesos oro impuesto a la harina estadunidense introducida en el territorio nacional, específicamente los costales que llegaban a Puerto Berrío y que se comercializaban en el interior del país. Dicho gravamen fue implantado a la harina en 1906, y eliminarlo implicaría la depreciación de la harina producida con el trigo cultivado en Cundinamarca y Boyacá, por lo que consideraban que la petición la debían elevar todas las municipalidades de la sabana en donde la industria del trigo era el principal medio de subsistencia de sus habitantes.

Los firmantes, en su mayoría agricultores de la sabana de Bogotá, argumentaban que, debido a las políticas proteccionistas implementadas cinco años atrás a favor de los intereses de este gremio, se habían realizado inversiones de consideración materializadas en maquinarias y técnicas implementadas en el cultivo, que rebasaban los 4000000 de pesos, inversión que engrosaría, según el gremio de agricultores, los bolsillos del país del tío Sam, si tal decreto era suprimido. "Innumerable es la cantidad de brazos que derivan su existencia del cultivo de este grano, cuya producción hoy no puede estimarse, debido a su visible diario incremento, en menos de CUATRO MILLONES PESOS ORO, que, en gran parte, al sostenerse ese decreto irían a engrosar los bolsillos de los yanquis [sic]" (La Civilización, 10 de marzo de 1910).

Las demandas de estos productores de la sabana de Bogotá tendrían una participación clave en la política aduanera y fiscal del entrante gobierno de Carlos E. Restrepo, que se posesionaría a partir del 7 de agosto de 1910. Restrepo tomaría medidas de importancia trascendental que irían en contravía de las tomadas por el gobierno de Reyes, lo que cambiaría en mucho la relación entre el gobierno y un sector de empresarios de la costa que veía en estos cambios un atentado inmediato a sus intereses económicos.

\section{El gobierno de CARlos E. Restrepo y los CONFLictos CON LOS COMERCIANTES Y PRODUCTORES DE HARINA}

En 1910, Carlos E. Restrepo, el principal opositor de Rafael Reyes, asumió la presidencia de Colombia tras la elección de la Constituyente reunida el 15 de mayo y, como era de esperarse, ni el gobierno de Reyes ni el provisional de González Valencia lograron superar la situación deficitaria del Estado, lo que motivó que Restrepo hiciera grandes cambios a la política económica y fiscal del país, contando entre los más importantes la eliminación de la vicepresidencia y su reemplazó por la figura de primero y segundo designado. Además, pasó al presidente el poder de elegir magistrados de la Corte Suprema de Justicia; impidió la inmediata reelección 
del presidente y recortó su periodo a cuatro años; devolvió al Congreso de la República la facultad de aprobar las decisiones presidenciales en relación con los convenios internacionales; introdujo la votación directa para elección de presidente, aunque sólo para quienes supieran leer y escribir o tuvieran renta de 300 pesos al año o propiedad de 1000 pesos, y restableció las asambleas departamentales con cierta autonomía administrativa. Aunado a lo anterior, suprimió la pena de muerte y eliminó la emisión de papel moneda de curso forzoso. Estas reformas, finalmente, expresaban la concepción política de la Unión Republicana que, sin duda, fue una manera de acomodar el Estado colombiano a las nuevas necesidades económicas del país y a la fortaleza que tomaban las exportaciones de café, apoyadas en la productividad que experimentaba el grano en la región antioqueña (Bergquist, 1992; Melo, 1996; véanse también Kalmanovitz, 1994 y Ocampo, 1984). Como era de esperarse, Restrepo iniciaría una revisión de la política proteccionista de Reyes. Asimismo, estimó que era necesario realizar cambios en el sistema de tarifas y aranceles, ya que tal como estaba concebido causaría la ruina del fisco nacional.

Aunque en su mayoría estas políticas fueron pensadas desde el Ministerio de Hacienda por Tomas Eastman, encargado de esta cartera, las nuevas disposiciones fueron desarrolladas y aplicadas por Francisco Restrepo Plata, quien asumió el ministerio después de la pronta renuncia de Eastman. El nombramiento de Restrepo Plata causó malestar en diferentes sectores políticos del país y un rechazo inmediato.

[...] debía recaer sobre una persona de reconocidas capacidades financieras capaz de resolver satisfactoriamente la crisis fiscal que cada día más agobiaba a la Nación. Desde La Capital, diario liberal, propiedad de J. M. Pérez Sarmiento, se publicaba en la columna "Lo que se dice" que una de las personas más idóneas para detentar dicho cargo era Ernesto Michelsen, por su destacada labor en el Banco de Colombia. Además, Restrepo Plata gozaba de un amplio rechazo entre los costeños por haber asegurado que "entre aquellos no había un hombre honrado digno de administrar las rentas nacionales" (La Capital, 12 de enero de 1911).

El ministro de Hacienda en el plan fiscal creado para 1910 propuso la puesta en marcha de la Ley 85, que comprendía un amplio número de disposiciones fiscales para aplicarse en todos los ministerios. Esta ley, creada por el anterior ministro Eastman, fue emprendida por Restrepo Plata; contempló la reducción de los sueldos de los empleados nacionales, que empezaría desde el propio gobierno, y se ajustaría a la siguiente escala:

Los sueldos de trescientos pesos (\$300) o mayores, en su treinta por ciento (30 por 100). 
Los sueldos de doscientos cincuenta pesos $(\$ 250)$, a trescientos pesos $(\$ 300)$ en un veinticinco por ciento (25 por 100).

Los sueldos de doscientos cincuenta pesos o menores (\$250), en un veinte por ciento (20 por 100) (La Mañana, 8 de enero de 1910).

Según el periódico La Mañana, el gobierno recibió un voto de confianza en el asunto de sueldos. A este voto debía corresponder el gobierno para que la ley fuese una norma de cumplimiento obligatorio y se aplicase de manera justa y rigurosa dependiendo de las categorías salariales y no de "las simpatías que gocen y de la amistad que los una a sus jefes" (8 de enero de 1910). Además de estos ajustes salariales, en el nuevo proyecto que el ministro presentó al Congreso de la República se insinuaba como medida conveniente gravar con impuestos algunos artículos de exportación para atender a las demandas necesarias del movimiento económico, fiscal y político de la nación. Esta medida no gozó del mismo respaldo que tuvo la del ajuste salarial, sobre todo porque se oponía a los intereses de un grupo de comerciantes de la costa. "Hemos de decir que somos partidarios de los tales impuestos, aunque sea en determinados artículos; pero creemos que hoy por hoy el señor Restrepo Plata va un poco distanciado, porque, aunque se llenaría el objeto que hoy persigue, por otra parte, tal vez, produciría un mal interior en el país" (El Mundo Nuevo, 20 de septiembre de 1912).

La propuesta presentada por el ministro Francisco Restrepo Plata al Congreso era un fuerte cuestionamiento a las industrias exóticas y a las medidas proteccionistas emitidas por Rafael Reyes, disposiciones que cobijaban las industrias harineras, en especial las de la costa, entre estas la firma Urueta, Salcedo \& Co., de la cual Tomás Suri Salcedo era uno de los socios. Suri Salcedo pertenecía al liberalismo de corte radical, férreo opositor de la Unión Republicana, partido liderado por Carlos E. Restrepo y en el que confluían algunos miembros del liberalismo y el conservadurismo pensando que era posible establecer intereses comunes a través de la concertación y la alterabilidad en el gabinete ministerial (Melo, 1996, p. 226).

El presidente Restrepo apoyó resueltamente las iniciativas de su ministro; argumentó que eran muy poco razonables las leyes protectoras porque estas desarrollaron en el país industrias exóticas basadas en la elaboración de materias ya manufacturadas en el exterior, que, según el presidente, habían causado un quebranto a las rentas de aduanas de 1000000 de pesos en 1911 (La Crónica, 31 de julio de 1912). Entonces resultaba necesario que el Congreso resolviera si se limitaba el ensanche de esas industrias, que podían perjudicar al fisco en 3000000 de pesos antes de pocos años.

Desde el gabinete ministerial no sólo se criticaba la política proteccionista, sino que se argumentaba que esas medidas sólo beneficiaban a determinadas industrias, como era el caso de los molineros de la costa, afectando 
a las industrias harineras del interior del país. Según el ministro, el primer paso para acabar definitivamente con las disparidades de intereses y la lucha por los mercados de la harina en el interior del país era efectuar una reforma radical a la tarifa de aduanas vigente, por lo que desde abril de 1912 fue creada la Comisión de Tarifa de Aduanas sin la participación de los empresarios costeños ni de la mayoría de los productores del centro del país.

Esta comisión quedó conformada por Samuel Montaña, Simón Hurtado, Ernesto A. Gaitán, José D. Araujo, Luis Cuervo Márquez, Wenceslao Paredes, Sergio A. Burbao, Carlos Liévano y Ricardo Lleras Codazzi. El penúltimo de los miembros, en representación de la Sociedad de Agricultores de Colombia, estaría encargado de revocar la tarifa de aduanas vigente. Dicho proyecto sería discutido en las reuniones sucesivas entre el Congreso, las Cámaras de Comercio y el gremio de comerciantes. Desde la prensa oficial se señalaba: "Hasta ahora no se ha hecho nada definitivo en esta materia y que corresponda a las necesidades del país; que por tanto la tarea de la Comisión, además de lo delicada que es en sí misma, exige una pronta y acertada solución" (Diario Oficial, 26 de abril de 1912).

Básicamente, la Comisión de Tarifa de Aduanas retomaría las peticiones de la Sociedad de Agricultores de Colombia por los inconvenientes que tenía la tarifa vigente en la producción y comercialización de la harina en el interior del país.

El asunto del trigo y las harinas se había convertido en estos años en una de las principales preocupaciones para el Ministerio de Hacienda, pero los memoriales que enviaban los molineros al gobierno se reducían a defender sobre todo la utilidad que debía corresponderles y en ningún momento se contemplaba la idea de proteger los intereses de los consumidores, es decir, el direccionamiento de las políticas arancelarias no estaba encaminado a la disminución de los precios del pan, lo que iba en contravía a lo adelantado en otros países. Para este mismo año, el gobierno francés suprimió el impuesto de 75 francos por tonelada de trigo importado, "ese artículo había subido allá a mediados de mayo a 60 pesos la tonelada, al tiempo que en Londres sólo valía \$44, en Chicago \$43-57 y en Buenos Aires \$38" (La Crónica, 22 de agosto de 1912). En Colombia se mantenía a 70 pesos la tonelada de harina y, lo que era más grave, quería aumentarse a 100 pesos, hecho que de cumplirse agravaría la situación de los consumidores.

\section{LA JUNTA DE AGRicultores DEL INTERIOR DEL PAÍS Y SUS DEMANDAS}

La atención que desde el Ministerio de Hacienda se le dio al tema de la harina generó un ambiente propicio para que la Junta de Agricultores y los agricultores independientes de Bogotá presionaran al gobierno en di- 
ferentes direcciones; acusaban también al jefe de la sección de agricultura del ministerio de hacer caso omiso de sus solicitudes y, sobre todo, de tener una conducta hostil hacia los miembros de la junta. Esto llevó a que el organismo realizara una protesta pública en varios informativos capitalinos y ante la Comisión de la Cámara de Representantes. Los directivos argumentaban que era obviado el deber que tenía la Junta de Agricultores de trabajar por los intereses agrícolas del país y de no ponerse al servicio de un grupo en particular, en perjuicio de los consumidores; para ellos era importante que todos los organismos encargados de esta sección tuvieran como fin último buscar el abaratamiento de la producción y no el fomento de la especulación y el monopolio.

Por su parte, los agricultores de Bogotá no hacían más que quejarse de las pérdidas que les producía la venta del trigo a diez pesos la carga de once arrobas, mientras que, "en Europa y Estados Unidos, se vendían a \$4 y \$5” (La Crónica, 6 de noviembre de 1912); con este valor y las técnicas agrícolas poco modernas, era imposible el progreso de esta industria. Los agricultores indicaban que mientras no se tomaran medidas preventivas contra las heladas, el ramo no podría tener mayor progreso en la agricultura nacional.

Los agricultores y productores de trigo de Cundinamarca y Boyacá presionaron al gobierno a tomar partido frente a sus intereses, para lo que recurrieron a las elecciones con el objeto de promover candidatos de su confianza que los representaran ante el gobierno. La Sociedad de Fomento Agrícola, en nombre de su secretario, Juan Antonio Montoya, y sus demás miembros, Evaristo Herrera, Enrique Umaña S., Benjamín Gaitán, Julio Z. Torres, Jesús Rozo Ospina y Eustasio Santamaría, apelaron a los medios de información y llamaron la atención de los ciudadanos en los municipios del departamento de Cundinamarca para que eligieran diputados a la Asamblea Nacional Constituyente relacionados de manera directa con esta industria, es decir, individuos que pudieran contribuir de manera determinante en la creación de leyes que definieran los derechos de aduana y protegieran la industria harinera, gravemente amenazada por la competencia extranjera. En el acta que resultó, la Sociedad de Fomento Agrícola decidía:

1. Llamar la atención de los consejeros y demás ciudadanos de los municipios a fin de que hagan recaer la elección para diputados a la Asamblea Nacional Constituyente en personas que hallen identificadas con el principio de defensa de la industria nacional, consagrando en las leyes medidas que permitan el desarrollo de las capacidades de los colombianos en conformidad con su suelo y con sus climas, sus vías de comunicación y la pobreza que actualmente los agobia. 
2. Hacer presente a los honorables consejeros municipales que esta sociedad está dispuesta a oír cuantas consultas puedan hacérsele en el particular ( La Civilización, 15 de marzo de 1910).

Estas presiones políticas no eran únicamente de parte de los productores de harina de la meseta cundiboyacense, también los empresarios de este producto en la costa realizaron peticiones, denuncias y presiones para evitar una política arancelaria contraria a sus intereses. Para los empresarios costeños, el nuevo arancel aduanal, que según el ministro Restrepo Plata no alteraría ni perturbaría en nada las operaciones comerciales, era dañino para el progreso de la industria harinera nacional.

Mientras en el Club Cartagena los empresarios del sector discutían el tema de las alzas arancelarias para la harina y lo denunciaban por la prensa, los empresarios molineros de Barranquilla, liderados por Tomás Suri Salcedo, uno de los propietarios del Molino de la Nevada, publicaron un memorial dirigido al ministro de Hacienda, Francisco Restrepo Plata, demostrando, entre otras cosas, las inconveniencias que traería la implementación de una nueva tarifa de aduanas.

\section{LAS DEMANDAS DE LOS EMPRESARIOS DE LA HARINA EN LA COSTA}

La política fiscal y arancelaria de Carlos E. Restrepo enfrentó duros cuestionamientos por parte de los empresarios cundiboyacenses y costeños, además, como primer mandatario, tuvo que lidiar con los enfrentamientos de estos sectores por el control de los mercados de la harina en el país (véanse Dávila, 2003; Dávila, Viloria y Elías-Caro, 2013; Solano y Conde, 1993; Viloria, 2001). Así como los productores de trigo y comerciantes de harina de Bogotá y sus alrededores demandaron la atención del gobierno para que emitiera una política que defendiera los intereses de este gremio, los empresarios y comerciantes de la harina en la costa también hicieron sus reclamos y peticiones al gobierno de Restrepo, en el marco de unas relaciones políticas que, aunque tensas, se mantuvieron estables (Elías-Caro y Renán, 2013, p. 320).

Uno de los primeros pronunciamientos de los comerciantes y empresarios costeños, durante el gobierno de Restrepo lo realizaron frente a las peticiones que hicieron los productores de trigo bogotano en el congreso de agricultores que se reunió en la capital de la república. Este congreso aprobó una proposición encaminada a pedir al Congreso la modificación de la tarifa de aduana, específicamente que autorizara el aumento del gravamen de cuatro centavos el impuesto a la harina extranjera importada a territorio nacional, que para ese entonces pagaba un centavo, más $2 \%$. 
Desde el periódico La República se expresó la inconformidad de un sector de los empresarios de esta ciudad, preguntando: “ ¿Han meditado bien los señores del Congreso Agrícola las consecuencias que puede traer su pretensión? Han olvidado que un impuesto injusto colmó la medida de los pueblos explotados precipitándolos hasta llegar a desastrosas soluciones" (31 de julio de 1911).

Los debates alrededor de las tarifas de aduanas no eran nada nuevo, los redactores de $E l$ Progreso traían a colación el memorial presentado al ministro de Obras Públicas en el que se pedía la imposición de gravámenes a las velas esteáricas que se trabajaban en la costa. El decreto estaba próximo a expedirse pero "los señores Lequerica Hermanos, honorables industriales de esta plaza, productores del artículo, se pusieron en marcha y pudieron parar el golpe a tiempo". Los hermanos Lequerica enviaron sus productos por el ferrocarril Cartagena-Calamar aprovechando que a los que iban de bajada se los exceptuaba del pago del derecho fluvial; pese a eso, se les obligó al pago de gravámenes, alegando que el decreto que eximía del pago del derecho fluvial de los artículos de bajada sólo cobijaba "a los productos del interior, no a los de la costa". Al comercio de esta plaza se le exigía el pago del derecho fluvial de las embarcaciones que conducían mercaderías para el puerto marítimo de Tolú para ser internadas a las sabanas de Corozal sin pasar por ningún río. La harina, aunque generaba el debate central en la reforma a los aranceles, no era el único, otros ramos de la industria costeña se vieron igualmente afectados.

La principal preocupación de los empresarios de harina en la costa fue que, una vez estatuido el nuevo impuesto al trigo, cesaran las importaciones y que el gobierno estadunidense, en represalia, impusiera fuertes gravámenes a los productos colombianos que se consumían en ese país. Para los empresarios harineros de la costa era claro que la pretensión de la Junta de Agricultores era poco realizable si se quería volver obligatorio el consumo de la harina de trigo proveniente del interior del país, pues los molinos de Cundinamarca y Boyacá debían proporcionar 25000 toneladas de trigo que se consumían en Cartagena y Barranquilla, cosa que no era posible. "Estos molinos tienen una producción de harina diaria de dos mil quinientas arrobas $\dot{i}$ Puede del interior venir trigo para satisfacer esta producción? Claro que no. Y a cómo saldría costando el bushel de trigo puesto en Barranquilla y Cartagena" (El Comercio, 31 de julio de 1911).

Por otro lado, los empresarios costeños advertían los efectos colaterales que traería esta medida, argumentando primero que, si este derecho era aumentado a cuatro centavos como lo solicitaba la Junta de Agricultores, eso significaría la disminución de las introducciones a los molinos de La Nevada y El Caribe, lo que implicaría proporcionalmente la disminución en las contribuciones fiscales. "Se triplicaría el valor de las harinas por 
la escasez de la producción y el exceso de la demanda, lo cual constituiría más de una triple ganancia para estos centros industriales" (La República, 12 de agosto de 1912). La imposición de tal gravamen sólo traería como consecuencia el advenimiento de uno de los periodos más críticos para la industria harinera de la costa, lo que tendría un gran impacto para la economía regional, ya que los molinos que existían en la ciudad de Barranquilla producían pan para el consumo interno, y, además, el residuo de la molienda, el salvado, se desaprovecharía como un eficaz recurso para la alimentación de los animales en agosto, cuando era escaso el maíz y, sobre todo, se perderían las ganancias por su exportación a las "islas inglesas de Trinidad y Barbados" (La República, 12 de agosto de 1911).

Segundo, denunciaban que no sólo los empresarios molineros de la costa se verían afectados por este tipo de medidas que eran objeto de álgidos debates en el Congreso de Agricultores, ya que igualmente los consumidores se verían ampliamente perjudicados a la hora de consumir la harina del interior a precios mucho más altos, hecho que se agravaba porque el trigo que se producía en el interior era insuficiente para atender las necesidades del consumo en la costa caribe; además, dicha producción, en vez de aumentar, disminuía drásticamente, "pues, si antiguamente las cosechas daban el 40 por uno, hoy solamente producen el 14 por uno, debiéndose esto a que las tierras son aún cultivadas según los procedimientos primitivos y nadie se ha preocupado por emplear maquinarias y herramientas modernas" (El Progreso, 11 de agosto de 1912).

Por último, se cuestionaba la representatividad que tenía la Junta de Agricultores y el congreso que se realizaron en la ciudad capital, Bogotá. Para los redactores de los periódicos El Comercio, El Comercialy La Repúbli$c a$, era desconocida la labor que desempeñaba la Junta, así como era fácil suponer que durante el desarrollo de sus labores no habían participado "personas de la costa que fueran auténticos representantes de la región" ( $E l$ Comercial, 4 de agosto de 1911).

Además de las opiniones, reclamos y discusiones que se realizaron desde la prensa de Cartagena y Barranquilla, los empresarios dueños de la firma Urueta, Salcedo \& Co., propietarios de los molinos de La Nevada establecidos en Barranquilla, expusieron de manera directa su opinión, sus críticas y solicitudes al ministro de Hacienda, Francisco Restrepo Plata. Estos empresarios, en un detallado análisis sobre costos de importación, producción y traslado del trigo y la harina, intentaron persuadir al gobierno de lo inexacto que era afirmar que sus molinos causaban perjuicios a los productores de harinas y a los agricultores del interior de la república.

Para que los molinos de La Nevada y El Caribe pudieran producir 250 libras de harina (una carga) eran necesarios 190 kilos de trigo aproximadamente, lo que implicaba un gravamen de introducción de trigo de 1.90 
pesos y, una vez incrementado el impuesto en tres centavos, ascendería el de los 190 kilos a 5.70 pesos, lo que incidiría de manera directa en el precio de la carga de harina, que ahora sería de 20.25 pesos, carga de harina que se vendía en ese momento a 18.50 pesos. Para ellos era "evidente que, salvo un caso de locura en el que el pueblo consumidor prefiriese a este precio, el nuestro más alto, la ruina de nuestra industria sería a poco un hecho cumplido, pero en cambio la Nación habría atendido a la defensa del trigo de la Sabana de Bogotá" (Diego A. de Castro \& Co. y Urueta, Salzedo \& Co., 1912, p. 6).

El memorial enviado por Urueta, Salcedo \& Co. al ministro de Hacienda, Francisco Restrepo Plata, buscaba una manera de conciliar los intereses, es decir, exponía que el gravamen impuesto al trigo fuera proporcional al valor de la harina producida en Barranquilla y al de una tonelada de la misma calidad producida en Bogotá, "en este conflicto de intereses creo yo que lo más justo sea posible, y esa conciliación la encuentro en un impuesto al trigo extranjero, que iguale el valor de una tonelada de harina producida en Bogotá" (Diego A. de Castro \& Co. y Urueta, Salzedo \& Co., 1912, p. 6).

Otro de los puntos a los que se refirió el memorial fue a la propuesta de aumentar el gravamen al trigo impulsada por la Junta de Agricultores, ya que esta era inconsecuente porque el trigo sólo se importaba en la costa caribe, que funcionaba como centro productor y consumidor; en ningún momento se pensó en competir con la harina producida en los departamentos de Cundinamarca, Boyacá o Santander, y agregaban: "No comemos en la costa pan hecho con harina de Cundinamarca ni de Boyacá; siempre lo hemos hecho con harina, antes llamada de Castilla, hoy extranjera" (Diego A. de Castro \& Co. y Urueta, Salzedo \& Co., 1912, p. 6).

En los cálculos que se presentaban en el memorial se había tomado en consideración el derecho de internación de ocho centavos oro por cada kilogramo de harina, que sólo pagaba la industria harinera de la costa al subir los costales a Puerto Berrío; es decir, 9.20 pesos en cada carga, quedando claro que este derecho subía el valor de la harina que llegaba en el interior; se demostraba una vez más que el derecho de internación de la harina hacía competitiva la harina del interior, que no pagaba estos derechos. Además, era la harina de la costa la que le producía ingresos considerables al fisco de la nación. Agregaba el memorial que, con el aumento del consumo de harina en los últimos años, habían alcanzado un aumento de importancia los ingresos fiscales al país. "Desde el primero de enero de este año al día de hoy, 31 de mayo, la suma de $\$ 28189.25$ oro en cinco meses, en tanto que en todo el año de 1906 las introducciones de harinas extranjeras por esta Aduana, solo le produjeron al fisco \$61 984.73" (Diego A. de Castro \& Co. y Urueta, Salzedo \& Co., 1912, p. 10). 


\section{RESULTADOS DE LAS CONFRONTACIONES}

POR LA REFORMA DE LA TARIFA DE LA HARINA IMPORTADA

Luego de este intenso debate que se publicó en la mayoría de los diarios bogotanos, barranquilleros y cartageneros, el proyecto reformatorio de la tarifa de aduanas que había presentado el ministro de Hacienda, acogiendo las peticiones de los gremios agrícolas del país, fue sometido a un estudio pormenorizado: cerca de 90 días de intensa labor de sus miembros fueron necesarios para conciliar los intereses de los agricultores del interior del país y los empresarios molineros de Barranquilla, propietarios de los molinos de La Nevada y El Caribe. "Hasta donde fue posible se logró conciliar los diversos y poderosos intereses que entran en juego en tan complicado y trascendental problema" (El Tiempo, miércoles 30 de octubre de 1912).

La oposición de los empresarios harineros de la costa y de otros sectores sociales logró detener ese año las iniciativas arancelarias del gobierno. De 25 proyectos de ley que fueron presentados por el ejecutivo para desarrollar su plan de Hacienda, sólo se aprobaron siete, y se implementaron como leyes, la autorización al gobierno para el reconocimiento de varios créditos a cargo del Tesoro nacional, el contrato con la Anglo Colombian Investing Co., el reconocimiento de varios créditos a cargo del Tesoro nacional. La reforma propuesta por Restrepo Plata, basada en la reforma de la tarifa de aduanas, objeto de álgidos debates, presentada a consideración el 22 de julio de 1912, ni siquiera fue considerada para segundo debate. El primero de enero de 1913, en un mensaje dirigido a los colombianos, el presidente Carlos E. Restrepo dijo:

Si la tarifa no se votó, no dependió del gobierno, que cumplió con el deber, que no se había llenado en un cuarto de siglo, de presentar a las cámaras un proyecto de arancel que consultara todas las exigencias actuales, tanto desde el punto de vista fiscal, como desde el de los intereses de las industrias. La falta de tarifa y la incertidumbre en la que queda el país respecto de tan importante ramo perjudicará el desarrollo económico de la República y privará al Tesoro de cuantiosas entradas; dada la inseguridad en que quedamos en materia de aduanas, no podrá tener esta renta la grande expansión que era de esperarse (Diario Oficial, 30 y 31 de enero de 1913).

Desde el informativo El Centro se criticó la labor de Francisco Restrepo Plata por haber aplicado "su criterio trastornado de comerciante a los negocios públicos" (25 de febrero de 1913), específicamente por haber direccionado los proyectos ministeriales al aumento de las exportaciones en detrimento de los productos importados, sobre los cuales pesaban fuertes gravámenes. Para el ministro este resultado indicaba progreso, "sobre 
todo para los molineros de Bogotá, quienes hacían una ganancia excesiva" (25 de febrero de 1913), "criterios anacrónicos y poco viables”, ya que la prosperidad fiscal y económica de un país recaía principalmente sobre el movimiento comercial, el plan fiscal del ministro Restrepo Plata se había destacado por el aumento de las contribuciones de los colombianos, 70000000 de pesos habían salido del bolsillo de los ciudadanos hacia las arcas nacionales, "treinta meses a dos millones mensuales" que no se materializaban en obras de utilidad pública, de orden y seguridad; al contrario, dicha cantidad sólo estaba representada: "en desórdenes, agitaciones, en persecuciones, en atropellos provocados por el gobierno, en vergüenzas internacionales, en desastre y miseria, muerte de industrias y paralización de negocios, en un malestar económico incurable, proporcionado por la mala administración de las finanzas. iBendito gobierno!" (El Centro, 25 de febrero de 1913).

También desde la prensa de la costa fue cuestionada la labor de los representantes ante el poder central, ya que, si bien la harina y los comerciantes de este producto salieron de momento victoriosos, otros sectores de la economía de la costa se vieron afectados con la política fiscal de este gobierno. Se afirmaba que las causas de las injustas medidas que venían fraguándose desde la capital del país podrían encontrar su explicación en la falta de cohesión fraternal, lo que quedaba demostrado en la participación de los diputados en las Asambleas Nacionales, los ministros, senadores y representantes que hasta ese momento se habían destacado por un rotundo mutismo en cuanto al tema de las tarifas aduaneras, y agregaban: "No han dicho ni hecho cosa alguna que haga referencia siquiera a establecer un sistema arancelario de Aduanas que responda a las necesidades de la costa, que es, hoy por hoy, la más importante cuestión fiscal para el país, y especialmente para esta región" ("Por la costa", El Progreso, 11 de agosto de 1912).

Aunque a finales de 1912 el debate sobre los impuestos al trigo extranjero cesó y el gobierno dirigió su atención al café, que aumentó su demanda en el mercado internacional, elevando rápidamente los ingresos fiscales y, por consiguiente, la regularización de la moneda, 1913 sería un año para una nueva confrontación sobre el tema arancelario para la harina y el trigo importados. Para 1913 el ministro Restrepo Plata intentaría nuevamente realizar una reforma tributaria que buscaba proteger la producción del centro del país y, aunque no lo logró, el gobierno de Marco Fidel Suárez, en 1918, insistiría en la necesidad de realizar un ajuste a la tarifa de importación de este producto para evitar la ruina de los industriales del interior del país; en esa ocasión encontraría una oposición organizada alrededor de las demandas de la Liga Costeña, compuesta por varios sectores de la región (Posada, 1985). 


\section{Conclusiones}

Durante el periodo presidencial de Rafael Reyes, que se extiende de 1904 a 1909, miembros importantes del liberalismo barranquillero y del conservadurismo nacionalista cartagenero y barranquillero extendieron vínculos políticos económicos con el poder central, que dirigió sus políticas a la protección y el fomento de la iniciativa empresarial regional, vínculos que, aunque existentes, se irían debilitando en la medida en que el nuevo presidente Carlos E. Restrepo (1910-1914) intentó cambiar la política fiscal y derogar los decretos proteccionistas que amparaban las iniciativas empresariales de la costa. Desde el Ministerio de Hacienda, dirigido por Francisco Restrepo Plata, se crearon proyectos de ley orientados a aumentar los gravámenes sobre la harina importada, lo que iba en detrimento de la industria harinera en la costa caribe, representada por los empresarios molineros del Atlántico Urueta, Salcedo \& Co.

Para el periodo presidencial de Carlos E. Restrepo, además, se estimularía la centralización política y el desplazamiento del poder político de las elites regionales por miembros de la burocracia del centro del país. Lo trascendental de este esfuerzo encaminado a fortalecer la centralización política fue la reacción de las elites locales para hacer oposición a las medidas que se pretendían implantar desde el centro. Ante la amenaza de una pérdida de estatus de las elites del caribe colombiano en la vida política y económica nacional durante el periodo presidencial de Carlos E. Restrepo, la elite empresarial y política de la costa caribe diseñó dos estrategias de tipo coyuntural, la primera dirigida a fortalecer el liderazgo político de sus miembros y los proyectos tendentes a la descentralización y autonomía política ante el exceso de controles y tutelas sobre los poderes locales. La segunda consistió en realizar reivindicaciones dirigidas a defender los intereses económicos de los empresarios de la región mediante la oposición directa a las medidas fiscales del gobierno central y los intereses monopolísticos de los empresarios del interior del país. De esta manera, y utilizando alianzas y presiones de tipo político, lograron un equilibrio de poderes que se mantuvo en permanente tensión, hecho que caracterizó durante estos gobiernos las relaciones políticas de los empresarios de la costa con el gobierno central y los empresarios del centro del país.

\section{REFERENCIAS}

BALAN, J. (abril-junio, 1978). Una cuestión regional en la Argentina: burguesías provinciales y el mercado nacional en el desarrollo agro exportador. Desarrollo Económico 18(69), 49-87. 
Bell, G. (1991). Cartagena de Indias: De la colonia a la república. Santa Fe de Bogotá: Fundación Simón y Lola Guberek.

BELL, G. (octubre, 1994). Conflictos regionales y centralismo. Una hipótesis acerca de las relaciones políticas de la costa en los primeros años de la república (1821-1840). Revista de la Contraloría, 8, 49-68.

Bergquist, C. (1992). Café y conflicto en Colombia. Bogotá: El Áncora.

Botero, F. (2003). Estado, nación y provincia de Antioquia. Guerras civiles e invención de la región, 1829-1863. Medellín: Hombre Nuevo.

Calvo S. H. y Meisel A. (eds.) (1999). El rezago de la costa caribe colombiana. Bogotá: Banco de la República/Fundesarrollo.

CARdozO, G. (1998). Historia zuliana, economía, política y vida intelectual en el siglo XIX. Maracaibo: Universidad de Zulia.

CARdozo, G. (2005). Venezuela: de las regiones históricas a la nación. Caracas: Academia Nacional de la Historia.

Chambers, S. (1997). Los matices de la Ciudad Blanca: La cultura y sociedad urbana de Arequipa, Perú, 1780-1854. Revista de Ciencias Sociales, 3, 241-281.

Chambers, S. (2003). De súbditos a ciudadanos: honor, política y género en Arequipa, 17801854. Lima: La Red.

Chiaramonte, J. C., Cussianovich, E., y Tedeschi, S. (segundo semestre, 1993). Finanzas públicas y política interprovincial: Santa Fe y su dependencia de Buenos Aires en tiempos de Estanislao López. Boletín del Instituto de Historia Argentina y Americana Dr. Emilio Ravignani, 3a. serie, 8, 77-116.

Coerver, D. M. (abril, 1977). Federal state relations during the Porfiriato: The case of Sonora, 1879-1884. The Americas, 33, 567-584.

Colmenares, G. (1998). Varia. Selección de textos. Bogotá: Tercer Mundo.

Conde, J. (1994). Autonomía y rivalidades entre poblaciones en la provincia de Cartagena, 1810-1815. Historia y Cultura, 3, 69-78.

Conde, J. (2009). Buscando la nación. Ciudadanía, clase y tensión racial en el Caribe colombiano 1821-1855. Medellín: Universidad del Atlántico.

CONDORI, V. (2010a). Los efectos económicos de la Independencia en Arequipa: 18201824. En C. Contreras, C. Mazzeo y F. Quiroz (eds.), Guerra, finanzas y regiones en la historia económica del Perú (pp. 173-218). Lima: Instituto de Estudios Peruanos.

Condori, V. (2010b). Sociedad, identidad y regionalismo en Arequipa, 1780-1830. Historia, $9,47-71$.

Contreras, C. (1987). Mineros y campesinos en los Andes, mercado laboral y economía campesina en la Sierra Central, siglo XIX. Lima: Instituto de Estudios Peruanos.

CORRALES, I. T. (enero-marzo, 1982). Heterogeneidad del estado y conflictos regionales. Desaparición de poderes en Hidalgo. Revista Mexicana de Sociología, 44(1), 119-149.

DÁvila, C. (comp.) (2003), Empresas y empresarios en la historia de Colombia, siglo XIX-XX. Bogotá: Norma.

DÁvila, C., Viloria, J., y ElíAs-CARO, J. (2013). Los estudios empresariales en Colombia a principios del siglo XXI (con una referencia a México). Santa Marta: Universidad del Magdalena. 
Deustua, J. (1986). La minería peruana y la iniciación de la República. 1820-1840. Lima: Instituto de Estudios Peruanos.

Diego A. de Castro \& Co. y Urueta, Salcedo \& Co. (junio, 1912). La industria harinera de la Costa. Memoriales y escritos varios relacionados con dicha industria (pp. 6 y 10). Barranquilla: Imprenta del Comercio. Libros raros y manuscritos. Biblioteca Luis Ángel Arango Barranquilla, Colombia.

Elías-CARo, J. y Renán W. (2013). La educación superior en la provincia de Santa Marta y el Magdalena. Siglo XIX. Santa Marta: Universidad del Magdalena.

Flores, A. (1984). La ciudad sumergida. Aristocracia y plebe en Lima, 1760-1830. Lima: Mosca Azul.

Garavaglia, J. C. (2007). Construir el Estado, inventar la nación. El Río de la Plata, siglo XVIII-XIX. Tucumán: Prometeo Libros.

Girbal-Blacha, N. M. (1994). Azúcar, poder político y propuestas de concertación para el noroeste argentino en los años 20. Las conferencias de gobernadores de 1926-1927. Desarrollo Económico, 34(133), 107-122.

Hernández, E. (2008). La elite piurana y la independencia del Perú: la lucha por la continuidad en la naciente República (1750-1824). Lima: Instituto Riva Agüero/Pontificia Universidad Católica del Perú/Universidad de Piura.

Hidalgo (2008). Política, participación y ciudadanía en el proceso de independencias en la América andina. Quito: Fundación Konrad Adenauer.

Hunt, S. (1984). Guano y crecimiento en el Perú del siglo XIX. HISLA, Revista Latinoamericana de Historia Económica y Social, 4, 35-92.

Jaramillo, J. (1997). Travesías por la historia. Colombia: Presidencia de la República.

Kalmanovitz, S. (1994). Economía y nación. Una breve historia de Colombia. Bogotá: TM Editores.

Mallon, F. (1983). The defense of community in Peru's central highlands. Peasant struggle and capitalist transition, 1860-1940. Princeton: Princeton University Press.

ManriQue, N. (1987). Mercado interno y región. La Sierra Central. 1820-1930. Lima: Desco.

MARTínez, C. (octubre-diciembre, 1978). Alternativas de poder regional. Revista Mexicana de Sociología, Estado y Clases en América Latina 40(4), 1411-1428.

Mayor, A. (enero, 1999). Rafael Reyes. Revista Credencial Historia. Recuperado de http:// www.banrepcultural.org/blaavirtual/revistas/credencial/enero1999/109rafaelreyez. htm

Meisel, A. (1999). ¿Por qué perdió la costa caribe en el siglo xx? En Calvo S. H. y Meisel, A. (eds.), El rezago de la costa caribe colombiana. Bogotá: Banco de la República/Fundesarrollo.

Melo, J. O. (1996). La república conservadora. En Colombia hoy. Bogotá: Siglo XXI.

Múnera, A. (1993). Comerciantes de Cartagena y el conflicto regional con Santa Fe de Bogotá a principios del siglo XIX. Historia y Cultura, 1, pp. 17-29.

MúnerA, A. (julio-diciembre, 1996). El Caribe colombiano en la república andina: identidad y autonomía en el siglo XIX. Caribbean Studies, 29(2), 213-237. 
OcAmpo, J. A. (1984). Colombia y la economía mundial, 1830-1910. Bogotá: Siglo XXI/ Fedesarrollo.

PAlacio, M. (1986). Estado y clases sociales en Colombia. Bogotá: Procultura.

Palacio, M. y Safford, F. (2002). Colombia. País fragmentado, sociedad dividida. Su historia. Bogotá: Norma.

Peralta, V. (1991). En pos del tributo. Burocracia estatal, elite regional y comunidades indígenas en el Cusco rural, 1826-1854. Cusco: Centro de Estudios Regionales Andinos Bartolomé de las Casas.

PosadA, E. (1985). La Liga Costeña, una expresión de poder regional. Boletín Cultural y Bibliográfico, 21(3). Recuperado de http://www.banrepcultural.org/blaavirtual/ publicacionesbanrep/boletin/boleti3/bol3/liga.htm

PosAdA, E. (1999). El regionalismo político en la costa caribe de Colombia. En H. Calvo y A. Meisel (eds.), El rezago de la costa caribe colombiana. Cartagena: Banco de la República/Fundesarrollo.

Ripoll, M. T. (2003). Las redes familiares y el comercio en Cartagena. El caso de Rafael del Castillo y Compañía. 1861-1960. En C. DÁvila (comp.), Empresas y empresarios en la historia de Colombia, siglo XIX-XX (pp. 570-591). Bogotá: Norma.

Román, R. (2010). La crisis del puerto de Cartagena de Indias: conflictos y fracasos de sus proyectos de desarrollo. 1830-1848. En J. ElíAs-CARO y A. VidAl (eds.), Ciudades portuarias en la gran Cuenca del Caribe (pp. 335-395). Barranquilla: Universidad del Norte/Universidad del Magdalena.

Román, R. (2011). Celebraciones centenarias. La construcción de una memoria nacional en Colombia. Cartagena: Universidad de Cartagena/Alcaldía Mayor de Cartagena.

Rubbin, J. (2003). Descentrando el régimen: cultura y política regional en México. Boston: Universidad de Boston.

Solano, S. y CONDE, J. (1993). Elite empresarial y desarrollo industrial en Barranquilla, 1875-1930. Barranquilla: Universidad del Atlántico.

Taracena, J. A. (1997). Invención criolla, sueño ladino, pesadilla indígena. Los Altos de Guatemala: de región a Estado, 1750-1850. Costa Rica: Porvenir/Centro de Investigaciones Regionales de Mesoamérica/DRSCT.

Taracena, J. A. (septiembre, 2000). Región e historia. Cuadernos digitales: publicación electrónica en historia, archivística y estudios sociales, 1(2). Recuperado de http://historia.fcs.ucr.ac.cr/cuadernos/c2-his.htm

URdaneta, A. (2006). Intereses y rivalidades regionales en la Venezuela Caribeña. Memorias, 4(2), 1-53.

URDAneta, A. (diciembre, 2008). El Zulia del siglo XIX en la construcción de la nación en Venezuela. Revista de Ciencias Sociales, 14(3), 590-603.

Uribe, M. T. y Álvarez, J. (1987). Poderes y regiones en la constitución de la nación colombiana 1810-1850. Medellín: Universidad de Antioquia.

Viloria, J. (2001). Ganaderos y comerciantes en Sincelejo, 1880-1920. Cuaderno de Historia Económica y Empresarial, 8. Cartagena: Banco de la República. 